\title{
Radiodensity of intraventricular hemorrhage associated with aneurysmal subarachnoid hemorrhage may be a negative predictor of outcome
}

\author{
Ha Son Nguyen, MD, Luyuan Li, MD, Mohit Patel, BS, Shekar Kurpad, MD, PhD, and \\ Wade Mueller, MD
}

Department of Neurosurgery, Medical College of Wisconsin, Milwaukee, Wisconsin

\begin{abstract}
OBJECTIVE The presence, extent, and distribution of intraventricular hemorrhage (IVH) have been associated with negative outcomes in aneurysmal subarachnoid hemorrhage (SAH). Several qualitative scores (Fisher grade, LeRoux score, and Graeb score) have been established for evaluating SAH and IVH. However, no study has assessed the radiodensity within the ventricular system in aneurysmal SAH patients with IVH. Prior studies have suggested that hemorrhage with a higher radiodensity, as measured by CT Hounsfield units, can cause more irritation to brain parenchyma. Therefore, the authors set out to investigate the relationship between the overall radiodensity of the ventricular system in aneurysmal SAH patients with IVH and their clinical outcome scores.
\end{abstract}

METHODS The authors reviewed the records of 101 patients who were admitted to their institution with aneurysmal SAH and IVH between January 2011 and July 2015. The following data were collected: age, sex, Glasgow Coma Scale (GCS) score, Hunt and Hess grade, extent of SAH (none, thin, or thick/localized), aneurysm location, and Glasgow Outcome Scale (GOS) score. To evaluate the ventricular radiodensity, the initial head CT scan was loaded into OsiriX MD. The ventricular system was manually selected as the region of interest (ROI) through all pertinent axial slices. After this, an averaged ventricular radiodensity was calculated from the ROI by the software. GOS scores were dichotomized as $1-3$ and $4-5$ subgroups for analysis.

RESULTS On univariate analysis, younger age, higher GCS score, lower Hunt and Hess grade, and lower ventricular radiodensity significantly correlated with better GOS scores (all $p<0.05$ ). Subsequent multivariate analysis yielded age (OR 0.936, 95\% Cl 0.895-0.979), GCS score (OR 3.422, 95\% Cl 1.9-6.164), and ventricular density (OR $0.937,95 \% \mathrm{Cl}$ $0.878-0.999)$ as significant independent predictors $(p<0.05)$. A receiver operating characteristic curve yielded $12.7 \mathrm{HU}$ (area under the curve $0.625, p=0.032$, sensitivity $=0.591$, specificity $=0.596$ ) as threshold between GOS scores of $1-3$ and $4-5$.

CONCLUSIONS This study suggests that the ventricular radiodensity in aneurysmal SAH patients with IVH, along with GCS score and age, may serve as a predictor of clinical outcome.

https://thejns.org/doi/abs/10.3171/2016.11.JNS152839

KEY WORDS aneurysmal subarachnoid hemorrhage; radiodensity; CT Hounsfield units; vascular disorders

$\mathrm{U}$ P to $30 \%-70 \%$ of patients with aneurysmal subarachnoid hemorrhage (SAH) also exhibit intraventricular hemorrhage (IVH). ${ }^{13,19}$ Several qualitative scores (Fisher grade, LeRoux score, and Graeb score) have been established for evaluating SAH and IVH. However, to our knowledge, no studies have assessed the radiodensity within the ventricular system in aneurysmal SAH patients with IVH. Radiodensity, as measured using CT Hounsfield units, has a positive correlation with the age of the hemorrhage. Prior studies have suggested that a hemorrhage with higher radiodensity can cause more irritation to brain parenchyma. ${ }^{31,32}$ Therefore, we investigated

ABBREVIATIONS AUC = area under the curve; GCS = Glasgow Coma Scale; GOS = Glasgow Outcome Scale; IVH = intraventricular hemorrhage; ROC = receiver operating characteristic; $\mathrm{ROI}=$ region of interest; $\mathrm{SAH}=$ subarachnoid hemorrhage.

SUBMITTED December 4, 2015. ACCEPTED November 21, 2016.

INCLUDE WHEN CITING Published online May 5, 2017; DOI: 10.3171/2016.11.JNS152839. 


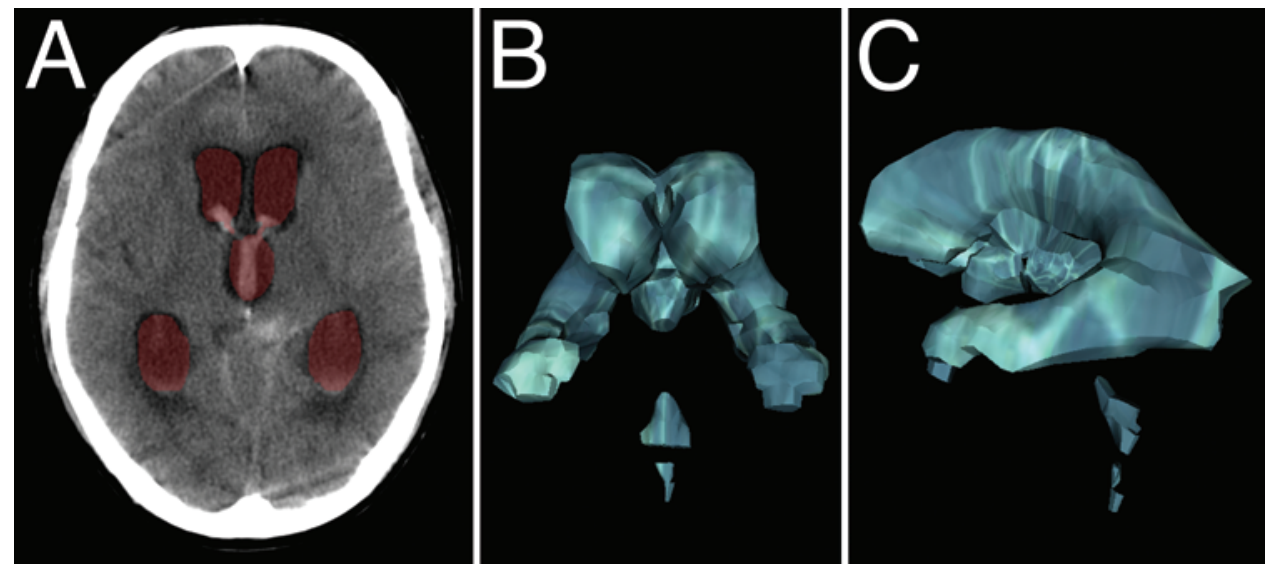

FIG. 1. A: Manual selection of ventricular system as an ROI. B and C: Modeling using OsiriX MD, where an average radiodensity is provided. Coronal $(B)$ and sagittal $(C)$ projections.

the relationship between the overall radiodensity of the ventricular system in aneurysmal SAH patients with IVH and their clinical outcome scores.

\section{Methods}

The approval of the institutional review board at our hospital was obtained prior to the study. To be considered for the study, the records of patients who were admitted for aneurysmal SAH between January 2011 and July 2015 were reviewed. Inclusion criteria were age greater than 18 years old, an available head CT scan demonstrating $\mathrm{SAH}$ prior to intervention (an external ventricular drain, clipping, or embolization), confirmed ruptured aneurysm on subsequent digital subtraction angiography, treatment with embolization, and presence of IVH. Exclusion criteria were the presence of vascular malformations, presence of intracranial artifacts (prior embolization or aneurysm clipping), and treatment with surgical clipping or open craniotomy. In total, 101 patients fulfilled the criteria for retrospective analysis. The medical records were reviewed, and the following data were extracted: age, sex, Glasgow Coma Scale (GCS) score at admission, Hunt and Hess grade, extent of SAH (none, thin $[<1 \mathrm{~mm}]$, and thick [>1 mm/localized]), location of the ruptured aneurysm (anterior or posterior circulation), and Glasgow Outcome Scale (GOS) score.

To evaluate the ventricular radiodensity, the initial head CT scan was loaded into OsiriX MD (Pixmeo). The ventricular system was manually selected as the region of interest (ROI) through all pertinent axial slices. Afterward, an averaged CT Hounsfield unit value was calculated from the ROI using the software (Fig. 1).

Statistical analysis was performed using IBM SPSS (version 22, IBM). Since the protocol required selection of the ventricular system, interobserver and intraobserver reliability calculations were performed with the use of the interclass correlation coefficient (where 0 represents no agreement and 1 represents perfect agreement). A value > 0.8 was considered an indication of excellent agreement.

For univariate analysis, continuous variables (age and ventricular radiodensity) and categorical variables (sex, GCS score, Hunt and Hess grade, extent of SAH, and an- eurysm location) were evaluated using ANOVA and Pearson's chi-square test, respectively. The main outcome variable was GOS score, which was dichotomized between GOS scores of 1-3 and 4-5. Subsequently, all variables with $\mathrm{p}<0.1$ from univariate analysis were used in a backward multivariate logistic regression, where the final variables in the model exhibited $\mathrm{p}<0.05$. A receiver operating characteristic (ROC) curve analysis was conducted to evaluate a threshold ventricular density for correlation with GOS score. A p value $<0.05$ was considered to be statistically significant.

\section{Results}

Interobserver and intraobserver correlation coefficients were 0.925 (95\% CI 0.887-0.951) and 0.997 (95\% CI 0.989-0.999), respectively, for the calculation of ventricular radiodensity.

Table 1 summarizes the univariate analysis. Younger age, higher GCS score, lower Hunt and Hess grade, and lower ventricular radiodensity significantly correlated with a better GOS score (all $\mathrm{p}<0.05$ ). Table 2 summarizes the multivariate logistics regression, where all of these variables were included initially. Age (OR 0.936, 95\% CI 0.895-0.979), GCS score (OR 3.422, 95\% CI 1.9-6.164), and ventricular density (OR $0.937,95 \%$ CI $0.878-0.999)$ were significant independent predictors $(\mathrm{p}<0.05)$. ROC curve, which optimized both sensitivity and specificity, yielded 12.7 HU (area under the curve [AUC] 0.625, p = 0.032 , sensitivity $=0.591$, specificity $=0.596$ ) as a threshold between GOS scores of 1-3 and 4-5 (Fig. 2).

\section{Discussion}

The incidence of aneurysmal SAH is approximately 7 per $100,000 .^{2}$ Overall outcome remains poor; the 30-day mortality rate can be as high as one-third of patients in prior studies, while survivors may continue to demonstrate significant long-term morbidity. ${ }^{2}$ Established factors associated with negative clinical outcomes and/or the need for long-term shunting, include presenting clinical demographics (age), neurological status (World Federation of Neurosurgical Societies [WFNS] and Hunt and Hess grades), ra- 
TABLE 1. Parameters for evaluation of GOS score

\begin{tabular}{|c|c|c|c|}
\hline Parameter & $\begin{array}{l}\text { GOS Scores } \\
1-3(n=44)\end{array}$ & $\begin{array}{c}\text { GOS Scores } 4 \\
\& 5(n=57)\end{array}$ & $\begin{array}{c}p \\
\text { Value }\end{array}$ \\
\hline Mean age (yrs) & $63.2 \pm 13.8$ & $56.5 \pm 10.1$ & $<0.01$ \\
\hline Sex & & & 0.881 \\
\hline Male & 11 & 15 & \\
\hline Female & 33 & 42 & \\
\hline GCS score & & & $<0.01$ \\
\hline$\leq 7$ & 23 & 7 & \\
\hline $8-14$ & 11 & 9 & \\
\hline 15 & 10 & 41 & \\
\hline $\mathrm{SAH}$ & & & 0.171 \\
\hline None & 3 & 1 & \\
\hline Thin & 12 & 24 & \\
\hline Thick/localized & 29 & 32 & \\
\hline Hunt \& Hess grade & & & $<0.01$ \\
\hline$|-|||$ & 17 & 50 & \\
\hline IV \& V & 27 & 7 & \\
\hline $\begin{array}{l}\text { Location of aneurysm } \\
\text { (circulation) }\end{array}$ & & & 0.32 \\
\hline Anterior & 29 & 32 & \\
\hline Posterior & 15 & 25 & \\
\hline $\begin{array}{l}\text { Mean ventricular } \\
\quad \text { radiodensity }(\mathrm{HU})\end{array}$ & $18.7 \pm 12.5$ & $13.4 \pm 6.6$ & $<0.01$ \\
\hline
\end{tabular}

Values are presented as the number of patients (\%) unless stated otherwise. Mean values are presented with SD.

diographic findings (Fisher score), and clinical course (early hydrocephalus requiring an external ventricular drain, vasospasm, and aneurysmal rehemorrhage) . $, 14,30,34,37^{\text {The }}$ presence, extent, and distribution of IVH have been associated with a poor prognosis. ${ }^{2,6,25,34}$ Furthermore, the clearance of IVH with tissue plasminogen activator has been the target of ongoing studies. ${ }^{11,12}$ Although qualitative scores (original and modified Fisher grade, ${ }^{3}$ LeRoux score, ${ }^{15}$ and original and modified Graeb score ${ }^{1,6,21}$ ) have been established for evaluating SAH and IVH, assessment of hemorrhage qualitatively can be inconsistent and imprecise. ${ }^{27}$

A recent study positively correlated the radiodensity of intracerebral hemorrhage to perihemorrhagic edema, suggesting that radiodensity may play a role in evaluating brain irritation/injury and predict clinical outcome ${ }^{32}$ Brain irritation may be related to a secondary cascade mediated by components of coagulation and products of clot breakdown. No studies have assessed the radiodensity of IVH in aneurysmal SAH patients as a quantitative marker. This study suggests that the ventricular radiodensity, along with

TABLE 2. Multivariate logistics regression

\begin{tabular}{lccc}
\hline \multicolumn{1}{c}{ Variable } & OR & $95 \% \mathrm{Cl}$ & $\mathrm{p}$ Value \\
\hline Age & 0.936 & $0.895-0.979$ & $<0.01$ \\
\hline Ventricular radiodensity & 0.937 & $0.878-0.999$ & 0.046 \\
\hline GCS score & 3.422 & $1.9-6.164$ & $<0.01$ \\
\hline
\end{tabular}

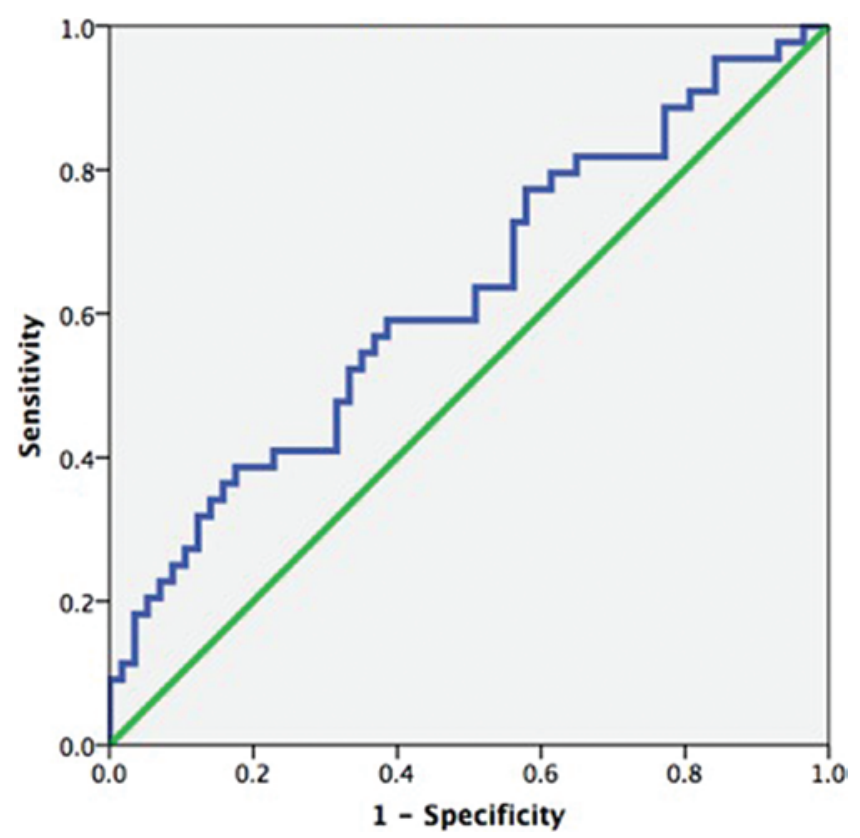

FIG. 2. ROC curve for ventricular radiodensity to determine GOS scores of $1-3$ versus $4-5$ (AUC $0.625, p=0.032$, value at $12.7 \mathrm{HU}$ with sensitivity $=0.591$ and specificity $=0.596)$.

age and GCS score, may also serve as a predictor for clinical outcome in aneurysmal SAH with IVH.

Degraded blood products may explain the relationship among radiodensity, hemorrhage, and clinical outcome..$^{35}$ Prior studies have indicated that hemoglobin, thrombin, and iron may contribute to perihemorrhagic edema, while the extent of edema has been correlated with poorer patient outcomes. ${ }^{7,32,35,36} \mathrm{In}$ studies in rats, iron depletion via deferoxamine tempers edema and enhances functional outcome after intracerebral hemorrhage is inflicted. ${ }^{23,32} \mathrm{In}$ the clinical setting, a higher serum ferritin level has been associated with additional perihemorrhagic edema and poorer outcomes in patients who have sustained a spontaneous intracerebral hemorrhage. ${ }^{20,32}$ Wagner et al. ${ }^{32}$ noted that a higher radiodensity of hemorrhage, associated with higher in vivo iron content, correlated with increased perihemorrhagic edema. Consequently, the authors believed that radiodensity might be an indirect measure of in vivo iron content within hemorrhage. Nevertheless, iron content is unlikely to explain all variations in radiodensity. ${ }^{32}$ The level of CSF proteins has also been positively correlated with the radiodensity of IVH. Moreover, elevated levels of several CSF proteins have been linked with poorer prognosis in aneurysmal SAH patients. ${ }^{4,5,9-11,16-18,22,24,26,28,29,33,38,39}$

This study had several limitations, including the small sample size and its retrospective nature. Moreover, the proposed method to calculate ventricular density involves manual selection of the ventricular system. This process requires some time with the potential to introduce ambiguities; however, the interobserver and intraobserver coefficients suggest a consistent and reliable protocol. In addition, the choroid plexus was also included in the ROI for the ventricular radiodensity, which may misleadingly elevate ventricular density. 


\section{Conclusions}

This study suggests that the ventricular radiodensity in aneurysmal SAH patients with IVH, along with GCS score and age, may also serve as a predictor for clinical outcome.

\section{References}

1. Czorlich P, Mende KC, Vettorazzi E, Regelsberger J, Westphal M, Schmidt NO: Validation of the modified Graeb score in aneurysmal subarachnoid hemorrhage. Acta Neurochir (Wien) 157:1867-1872, 2015

2. Czorlich P, Ricklefs F, Reitz M, Vettorazzi E, Abboud T, Regelsberger J, et al: Impact of intraventricular hemorrhage measured by Graeb and LeRoux score on case fatality risk and chronic hydrocephalus in aneurysmal subarachnoid hemorrhage. Acta Neurochir (Wien) 157:409-415, 2015

3. Fisher CM, Kistler JP, Davis JM: Relation of cerebral vasospasm to subarachnoid hemorrhage visualized by computerized tomographic scanning. Neurosurgery 6:1-9, 1980

4. Fountas KN, Tasiou A, Kapsalaki EZ, Paterakis KN, Grigorian AA, Lee GP, et al: Serum and cerebrospinal fluid Creactive protein levels as predictors of vasospasm in aneurysmal subarachnoid hemorrhage. Clinical article. Neurosurg Focus 26(5):E22, 2009

5. Goksu E, Goksu E, Karsli B, Akyuz M, Akbas H, Unal A, et al: Cerebrospinal fluid cystatin $C$ levels following treatment for aneurysmal subarachnoid hemorrhage. Turk Neurosurg 24:391-397, 2014

6. Graeb DA, Robertson WD, Lapointe JS, Nugent RA, Harrison PB: Computed tomographic diagnosis of intraventricular hemorrhage. Etiology and prognosis. Radiology 143:91-96, 1982

7. Hua Y, Keep RF, Hoff JT, Xi G: Brain injury after intracerebral hemorrhage: the role of thrombin and iron. Stroke 38 (2 Suppl):759-762, 2007

8. Jaja BN, Cusimano MD, Etminan N, Hanggi D, Hasan D, Ilodigwe D, et al: Clinical prediction models for aneurysmal subarachnoid hemorrhage: a systematic review. Neurocrit Care 18:143-153, 2013

9. Kaneda K, Fujita M, Yamashita S, Kaneko T, Kawamura Y, Izumi T, et al: Prognostic value of biochemical markers of brain damage and oxidative stress in post-surgical aneurysmal subarachnoid hemorrhage patients. Brain Res Bull 81:173-177, 2010

10. Kim JH, Yi HJ, Ko Y, Kim YS, Kim DW, Kim JM: Effectiveness of papaverine cisternal irrigation for cerebral vasospasm after aneurysmal subarachnoid hemorrhage and measurement of biomarkers. Neurol Sci 35:715-722, 2014

11. Kornbluth J, Nekoovaght-Tak S, Ullman N, Carhuapoma JR, Hanley DF, Ziai W: Early quantification of hematoma Hounsfield units on noncontrast CT in acute intraventricular hemorrhage predicts ventricular clearance after intraventricular thrombolysis. AJNR Am J Neuroradiol 36:1609-1615, 2015

12. Kramer AH, Jenne C, Holodinsky JK, Todd S, Roberts DJ, Kubes P, et al: Pharmacokinetics and pharmacodynamics of tissue plasminogen activator administered through an external ventricular drain. Neurocrit Care 23:386-393, 2015

13. Kramer AH, Mikolaenko I, Deis N, Dumont AS, Kassell NF, Bleck TP, et al: Intraventricular hemorrhage volume predicts poor outcomes but not delayed ischemic neurological deficits among patients with ruptured cerebral aneurysms. Neurosurgery 67:1044-1053, 2010

14. Lee VH, Ouyang B, John S, Conners JJ, Garg R, Bleck TP, et al: Risk stratification for the in-hospital mortality in subarachnoid hemorrhage: the HAIR score. Neurocrit Care 21:14-19, 2014

15. LeRoux PD, Haglund MM, Newell DW, Grady MS, Winn
HR: Intraventricular hemorrhage in blunt head trauma: an analysis of 43 cases. Neurosurgery 31:678-685, 1992

16. Lewis SB, Wolper R, Chi YY, Miralia L, Wang Y, Yang $\mathrm{C}$, et al: Identification and preliminary characterization of ubiquitin $\mathrm{C}$ terminal hydrolase 1 (UCHL1) as a biomarker of neuronal loss in aneurysmal subarachnoid hemorrhage. J Neurosci Res 88:1475-1484, 2010

17. Lewis SB, Wolper RA, Miralia L, Yang C, Shaw G: Detection of phosphorylated NF-H in the cerebrospinal fluid and blood of aneurysmal subarachnoid hemorrhage patients. J Cereb Blood Flow Metab 28:1261-1271, 2008

18. Martin J, Kagerbauer SM, Schuster T, Blobner M, Kochs EF, Landgraf R: Vasopressin and oxytocin in CSF and plasma of patients with aneurysmal subarachnoid haemorrhage. Neuropeptides 48:91-96, 2014

19. Mayfrank L, Hütter BO, Kohorst Y, Kreitschmann-Andermahr I, Rohde V, Thron A, et al: Influence of intraventricular hemorrhage on outcome after rupture of intracranial aneurysm. Neurosurg Rev 24:185-191, 2001

20. Mehdiratta M, Kumar S, Hackney D, Schlaug G, Selim M: Association between serum ferritin level and perihematoma edema volume in patients with spontaneous intracerebral hemorrhage. Stroke 39:1165-1170, 2008

21. Morgan TC, Dawson J, Spengler D, Lees KR, Aldrich C, Mishra NK, et al: The Modified Graeb Score: an enhanced tool for intraventricular hemorrhage measurement and prediction of functional outcome. Stroke 44:635-641, 2013

22. Nakahara T, Tsuruta R, Kaneko T, Yamashita S, Fujita M, Kasaoka S, et al: High-mobility group box 1 protein in CSF of patients with subarachnoid hemorrhage. Neurocrit Care 11:362-368, 2009

23. Okauchi M, Hua Y, Keep RF, Morgenstern LB, Xi G: Effects of deferoxamine on intracerebral hemorrhage-induced brain injury in aged rats. Stroke 40:1858-1863, 2009

24. Petzold A, Keir G, Kerr M, Kay A, Kitchen N, Smith M, et al: Early identification of secondary brain damage in subarachnoid hemorrhage: a role for glial fibrillary acidic protein. J Neurotrauma 23:1179-1184, 2006

25. Rosen DS, Macdonald RL, Huo D, Goldenberg FD, Novakovic RL, Frank JI, et al: Intraventricular hemorrhage from ruptured aneurysm: clinical characteristics, complications, and outcomes in a large, prospective, multicenter study population. J Neurosurg 107:261-265, 2007

26. Schoch B, Regel JP, Wichert M, Gasser T, Volbracht L, Stolke D: Analysis of intrathecal interleukin-6 as a potential predictive factor for vasospasm in subarachnoid hemorrhage. Neurosurgery 60:828-836, 2007

27. Siddiqui UT, Khan AF, Shamim MS, Hamid RS, Alam MM, Emaduddin M: Inter-observer variability in diagnosing radiological features of aneurysmal subarachnoid hemorrhage; a preliminary single centre study comparing observers from different specialties and levels of training. Surg Neurol Int 5:96, 2014

28. Sokół B, Woźniak A, Jankowski R, Jurga S, Wąsik N, Shahid $\mathrm{H}$, et al: HMGB1 level in cerebrospinal fluid as a marker of treatment outcome in patients with acute hydrocephalus following aneurysmal subarachnoid hemorrhage. J Stroke Cerebrovasc Dis 24:1897-1904, 2015

29. Suzuki H, Kanamaru K, Shiba M, Fujimoto M, ImanakaYoshida K, Yoshida T, et al: Cerebrospinal fluid tenascin-C in cerebral vasospasm after aneurysmal subarachnoid hemorrhage. J Neurosurg Anesthesiol 23:310-317, 2011

30. Tewari M, Aggarwal A, Mathuriya S, Gupta V: The outcome after aneurysmal sub arachnoid hemorrhage: a study of various factors. Ann Neurosci 22:78-80, 2015

31. Volbers B, Staykov D, Wagner I, Dörfler A, Saake M, Schwab S, et al: Semi-automatic volumetric assessment of perihemorrhagic edema with computed tomography. Eur J Neurol 18:1323-1328, 2011 
32. Wagner I, Volbers B, Hilz MJ, Schwab S, Doerfler A, Staykov D: Radiopacity of intracerebral hemorrhage correlates with perihemorrhagic edema. Eur J Neurol 19:525528, 2012

33. Wang KC, Tang SC, Lee JE, Lai DM, Huang SJ, Hsieh ST, et al: Prognostic value of intrathecal heme oxygenase-1 concentration in patients with Fisher Grade III aneurysmal subarachnoid hemorrhage. J Neurosurg 121:1388-1393, 2014

34. Wilson TJ, Stetler WR Jr, Davis MC, Giles DA, Khan A, Chaudhary N, et al: Intraventricular hemorrhage is associated with early hydrocephalus, symptomatic vasospasm, and poor outcome in aneurysmal subarachnoid hemorrhage. J Neurol Surg A Cent Eur Neurosurg 76:126-132, 2015

35. Wu J, Hua Y, Keep RF, Schallert T, Hoff JT, Xi G: Oxidative brain injury from extravasated erythrocytes after intracerebral hemorrhage. Brain Res 953:45-52, 2002

36. Xi G, Keep RF, Hoff JT: Mechanisms of brain injury after intracerebral haemorrhage. Lancet Neurol 5:53-63, 2006

37. Yang TC, Chang CH, Liu YT, Chen YL, Tu PH, Chen HC: Predictors of shunt-dependent chronic hydrocephalus after aneurysmal subarachnoid haemorrhage. Eur Neurol 69:296-303, 2013

38. Zanier ER, Longhi L, Fiorini M, Cracco L, Bersano A, Zoerle T, et al: Increased levels of CSF heart-type fatty acidbinding protein and tau protein after aneurysmal subarachnoid hemorrhage. Acta Neurochir Suppl 102:339-343, 2008

39. Zanier ER, Refai D, Zipfel GJ, Zoerle T, Longhi L, Esparza TJ, et al: Neurofilament light chain levels in ventricular cere- brospinal fluid after acute aneurysmal subarachnoid haemorrhage. J Neurol Neurosurg Psychiatry 82:157-159, 2011

\section{Disclosures}

The authors report no conflict of interest concerning the materials or methods used in this study or the findings specified in this paper.

\section{Author Contributions}

Conception and design: Nguyen. Acquisition of data: Nguyen, Li, Patel. Analysis and interpretation of data: all authors. Drafting the article: all authors. Critically revising the article: all authors. Reviewed submitted version of manuscript: all authors. Approved the final version of the manuscript on behalf of all authors: Nguyen. Statistical analysis: Nguyen. Administrative/technical/material support: Nguyen, Kurpad, Mueller. Study supervision: Nguyen, Kurpad, Mueller.

\section{Supplemental Information Previous Presentations}

This paper was presented at the 2016 Cerebrovascular Section Annual Meeting in Los Angeles, California, February 15-16, 2016.

\section{Correspondence}

Ha Son Nguyen, Department of Neurosurgery, Medical College of Wisconsin, 9200 West Wisconsin Ave., Milwaukee, WI 53226. email: hsnguyen@mcw.edu. 